\title{
Restriction of RecG translocation by DNA mispairing
}

\author{
Zhiqiang Sun ${ }^{1}$, Yaqing Wang ${ }^{1}$, Mohtadin Hashemi ${ }^{1}$, Piero R. Bianco ${ }^{1}$ \& Yuri L. Lyubchenko ${ }^{{ }^{*}}$ \\ ${ }^{1}$ Department of Pharmaceutical Sciences, University of Nebraska Medical Center, Omaha, NE 68198-6025, USA
}

\begin{abstract}
* To whom correspondence should be addressed: Yuri L. Lyubchenko: Department of Pharmaceutical Sciences, College of Pharmacy, University of Nebraska Medical Center, 986025 Nebraska Medical Center, Omaha, NE 68198-6025; Tel. 402-559-1971 (office); Email: ylyubchenko@unmc.edu.
\end{abstract}

Keywords: atomic force microscopy (AFM), RecG, DNA rescue, DNA replication, DNAprotein interaction

\begin{abstract}
The RecG DNA helicase plays a crucial role in stalled replication fork rescue as the guardian of the bacterial genome. We have recently demonstrated that single-strand DNA binding protein (SSB) promotes binding of RecG to the stalled replication fork by remodeling RecG, enabling the helicase to translocate ahead of the fork. We also hypothesized that mispairing of DNA could limit such translocation of RecG, which plays the role of roadblocks for the fork movement. Here, we used atomic force microscopy (AFM) to directly test this hypothesis and investigate how sensitive RecG translocation is to different types of mispairing. We found that a C-C mismatch at a distance of $30 \mathrm{bp}$ away from the fork position prevents translocation of RecG over this mispairing. A G-bulge placed at the same distance also has a similar roadblock efficiency. However, a C-C mismatch $10 \mathrm{bp}$ away from the fork does not prevent RecG translocation, as $10 \mathrm{bp}$ from fork is within the distance of footprint of RecG on
\end{abstract}


fork DNA. Our findings suggest that retardation of RecG translocation ahead of the replication fork can be a mechanism for the base pairing control for DNA replication machinery.

\section{Introduction}

The interplay between genetic recombination and DNA repair machinery is the key point for genome duplication, which is a highly accurate and processive process (1-3). However, genome duplication can be stopped by DNA template damage, arrested polymerase, and other DNA-protein interactions(4-7). These roadblocks stall the replication fork, and various mechanisms are involved in fork repair and restoring the replication process. RecG is one of the critical proteins that is involved in the restoration process. RecG is a powerful, monomeric, atypical DNA helicase that binds to stalled DNA replication forks and couples DNA unwinding to duplex rewinding, resulting in the extrusion of Holliday junctions(8). RecG binds specifically to the stalled replication fork, rewinds the parental strand DNA utilizing ATP hydrolysis, generates a Holliday junction (HJ), and allows the homologous DNA repair machinery to repair DNA and start the replication process(8-10).

In addition to directly binding to forks and processing them, RecG also physically and functionally interacts with the single-strand binding protein (SSB)(9-15). The physical interaction is utilized by RecG to bind to SSB already positioned on the fork, resulting in the loading of RecG onto duplex DNA, concomitant with helicase remodeling(16). After RecG's binding mode to the DNA fork being remodeled, RecG is able to spontaneously translocate in front of the fork DNA over distances as large as 200bp (17). We were able to directly visualize such thermally driven and ATP-independent translocation of RecG with time-lapse high-speed AFM (HS-AFM). These findings suggest that mispairing of the DNA duplex in front of the fork 
can limit the RecG translocation distance, thereby sending a signal to the replication machinery about potential problems with the DNA duplex ahead of the fork.

To investigate this hypothesis, we created forks with duplex imperfections in the parental dsDNA arm. The duplex imperfections include a C-C mismatch or a G-bulge, positioned either 10 or $30 \mathrm{bp}$ ahead of the fork (Fig. 1). While RecG can bind directly to forks, we have previously shown that SSB enhances the interaction of the helicase with forks. Therefore, each fork used in this study has a gap in the leading strand arm (the preferred fork for RecG), but this arm is $69 \mathrm{nt}$ in length to ensure efficient SSB binding, as before (10,16-18). The binding of RecG to each fork in the absence and presence of SSB was separately assessed using AFM. The interaction with SSB initiates RecG remodeling, defined by the elevated affinity of RecG to the fork. Insertions of the G-bulge and C-C mismatch $30 \mathrm{bp}$ away from the fork resulted in a decrease of the translocation distance from $48 \pm 13$ bp to $26 \pm 11$ bp and $26 \pm 10$ bp (S.D.), respectively. The CC mismatch placed $10 \mathrm{bp}$ from the fork has less of an effect on the translocation distance, allowing RecG to translocate over distances $30 \pm 11 \mathrm{bp}$ rather than stall at $10 \mathrm{bp}$. The explanation for this trend is given by the simulated structure of RecG-DNA complex(19), which showed that RecG covers 23 bp on the DNA duplex region. Mispairing at the $30 \mathrm{bp}$ distance hinders the protein translocation, while the mismatch $10 \mathrm{bp}$ away from the fork does not. These results reveal a novel function of RecG, in which it selects the DNA duplex quality of parental arm of the fork.

\section{Results and discussion}

\section{Fork DNA constructs}


Our constructs that mimic stalled DNA replication forks, with and without additional damage, are schematically shown in Fig. 1. Construct F4 represents a stalled replication fork with a gap in the nascent leading strand flanked by asymmetric DNA duplex regions (280 and 396 bp in length). Previously, we have used F4 to study RecG binding, which allowed us to distinguish between parental and lagging strand arms of the fork in AFM images(16). This type of replication fork is similar to the substrate in the crystallographic studies of T. maritima RecGDNA complexes ${ }^{(19)}$. Constructs F6, F7, and F8 are similar to F4, except they contain a mismatch or bulge in the parental duplex region. F6 contains a $\mathrm{C}-\mathrm{C}$ mismatch at $10 \mathrm{bp}$ ahead of the fork position. F7 contains a single G-bulge on the parental arm positioned $30 \mathrm{bp}$ upstream of the fork, while $\mathrm{F} 8$ contains a $\mathrm{C}-\mathrm{C}$ mismatch at the same position. The $\mathrm{C}-\mathrm{C}$ mismatch can change the local structure of DNA, including global helical bending, opening, and minor groove width in the center of the helix(20,21). The dynamics (breathing frequency) of local DNA of C-C mismatch suggests that $\mathrm{C}-\mathrm{C}$ mismatch is stronger than other kind of mismatches(22). The G bulge in the F7 construct contains an extra $\mathrm{G}$ on one ssDNA, and there is two $\mathrm{C}$ on each sides of $\mathrm{G}$, which makes it less stable than others(23). The mismatch or bulge positions were designed to be within the thermal sliding distance of SSB bound to a fork $(16,17)(24)$.

\section{SSB facilitates RecG binding to the fork constructs}

Previously, we found that SSB facilitates RecG binding to fork substrates(16). Here, we tested whether SSB can facilitate the binding of RecG to different fork constructs containing mispaired regions. The experiments for all substrates were performed in parallel. As shown in Fig. 2, when SSB and RecG are added sequentially to the reaction mixture, both proteins can be observed bound to the same DNA (indicated by the arrows). As reported previously(16), SSB and RecG can be readily discerned; this is displayed in the insets of Fig. 2, with the larger feature 
being SSB (blue arrow) and the smaller one being RecG (red arrow). Furthermore, for most DNA molecules with both proteins bound, SSB and RecG are at distinct positions, and seldom colocalize. There are some DNA molecules with only a single feature, and analysis shows that these are SSB (Fig. S1).

To assess the ability of SSB to load RecG onto the designed forks, we measured the yield of protein-DNA complexes in RecG only and SSB-RecG experiments. Results show that the yield of RecG complexes is higher when SSB is added first compared to RecG only (Fig. 3). The number of DNA-protein complexes varies from 50 to 80 . These data also show that when the duplex imperfection is positioned $10 \mathrm{bp}$ from the fork (Fork 6), binding of RecG is inhibited by 2-fold, regardless of the presence of SSB. In contrast, when the duplex imperfection is positioned $30 \mathrm{bp}$ away from the fork, RecG binding or SSB loading of the helicase is unaffected, with F7 and F8 substrates producing data similar to F4. This suggests that when the imperfection is within the RecG binding footprint with the fork, RecG binding is inhibited. Additionally, this also suggests that the initial loading site of RecG by SSB encompasses 10 base pair from the fork.

\section{The mispairing limits the translocation of RecG}

SSB can enhance the binding efficiency of RecG on all four different fork substrates; therefore, we investigated whether SSB can remodel RecG on all fork substrates and allow RecG to translocate over the arms of the fork. To do this, we mapped positions of SSB and RecG on F4, F6, F7, and F8 substrates, and the data is shown in Fig. 4 (A-D), respectively. SSB and RecG positions were measured relative to the same DNA end, usually the end of the parental strand (short arm). Since SSB binds specifically to the ssDNA, the position of SSB was set to 0. When 
RecG translocates to the parental strand, the position of RecG has a negative value (below SSB in the graph). When RecG translocates to the lagging strand, the position of RecG has a positive value (above SSB in the graph). Similar to our previous findings(16), when RecG binds to the fork DNA in the presence of SSB, RecG appears on the duplex arms of the fork. Furthermore, when translocating, RecG prefers the parental arm on all fork substrates. In control experiments in the absence of SSB, RecG binds precisely to the fork position (Fig. S2).

Translocation distance on the parental arm was investigated due to the fact that all mismatches are located on the parental arm of F6, F7, and F8. These translocation values are shown as histograms of RecG positions in Fig. 4 (E-H) for DNA substrates F4, F6, F7, and F8, respectively. The data show that RecG translocation distance is shorter on the fork substrates with C-C mismatch or G-bulge. For construct F4, RecG is loaded onto the parental strand arm in $75 \%$ of the cases, with the translocation distance being $48 \pm 13 \mathrm{bp}$. The arm preference for F6, F7, and F8 constructs are $60 \%, 75 \%$, and $74 \%$ for parental arm, respectively, while translocation distances are $30 \pm 11 \mathrm{bp}, 26 \pm 11 \mathrm{bp}$ and $26 \pm 10 \mathrm{bp}$. The shorter translocation distance, compared to on F4, suggests that the C-C mismatch and G-bulge can limit the translocation of RecG on the parental arm. Additionally, the translocation distances of RecG on F7 and F8 are very similar and match the position of the bulge and mismatch location (30 bp from fork position). The translocation distance of RecG on F6 also decreased compared to that on F4, but all the RecG were found at positions beyond $10 \mathrm{bp}$ away from the fork.

We hypothesized that RecG has a large footprint on the fork DNA, so the mismatch on F6 will be within the binding regions and cannot work as a roadblock. Fig. 5 shows that the footprint of RecG on the duplex DNA (green + red) is $23 \mathrm{bp}$, which is obtained from our previous RecG structure and simulations with a fork DNA substrate(19). This suggests that when 
the position of the DNA mismatch is more than $23 \mathrm{bp}$ away from the fork, it should not affect the binding of RecG to the fork. The mismatch at $10 \mathrm{bp}$ away from the fork on F6 is within the footprint of RecG. Thus, it can decrease the binding efficiency of RecG to the fork but cannot limit the translocation of RecG when RecG is bound to the fork. Indeed, the yield of RecG on F6, even in the presence of SSB, is lower than that on the other substrates. Interestingly, the translocation distance of RecG on the parental arm of F6 is still less than that on F4. This suggests that the $10 \mathrm{bp}$ mismatch location also affects the translocation of RecG, but to a lesser extent and through a possibly different mechanism compared to the mismatch located $30 \mathrm{bp}$ from the fork position.

Compared with narrow distributions of translocation distances on parental arms, the distances between SSB and the RecG on the lagging arm vary in a wide range (Fig. S3). There is no preferred translocation distance of RecG on the lagging strand. This suggests that while the translocation of RecG on the parental strand is limited by the mismatches $30 \mathrm{bp}$ from the fork, the lagging strand does not impose such a limit on the translocation of RecG since there is no mismatches on lagging strand arm. While most RecG translocated short distances from the fork, the data in Fig. S4 show that RecG can pass over the mispairings and translocate to distances up to $\sim 300 \mathrm{bp}$ on both arms of fork DNA, which was also observed in our previous findings(17). On F6 substrate, with the C-C mismatch 10 bp away from the fork, the frequency of long-range translocation is greater than that on the other fork substrates. This may be due to the mismatch located $10 \mathrm{bp}$ from the fork, which does not block the translocation, allowing RecG to move far beyond the mismatch position. On F7, majority of the RecG appeared on the lagging strand (Fig. S3 and S4) and far away from SSB (more than $50 \mathrm{bp}$ ). On F8, there were only a few RecG molecules translocating more than $50 \mathrm{bp}$. 
Overall, our data demonstrate that mispairings can act as roadblocks for spontaneous RecG translocation. Due to a large footprint of RecG on the DNA replication fork, the mispairing can be detected by RecG at distances beyond 20 bp. In those cases, the presence of RecG in front of the replication fork may act as a signal for the replication machinery to stop and for the repair process to start. The location of RecG in the proximity of the replication fork facilitates its participation in the fork regression process, which is the major function of RecG.

\section{Methods}

\section{Protein preparations.}

RecG protein was purified as described previously (25). Briefly, the protein was eluted using a linear salt gradient $(10-1000 \mathrm{mM} \mathrm{NaCl})$, with RecG eluting between 250 and $360 \mathrm{mM}$ $\mathrm{NaCl}$, on a $100 \mathrm{ml}$ Q-Sepharose column equilibrated in buffer A [20 mM Tris- $\mathrm{HCl}(\mathrm{pH} 8.5), 1$ mM EDTA, $1 \mathrm{mM}$ DTT, $10 \mathrm{mM} \mathrm{NaCl}$. The pooled fractions were then subjected to heparin FF and hydroxylapatite chromatography, as previously described (26). Pooled fractions from the hydroxylapatite column were dialyzed overnight into $\mathrm{S}$ buffer $[10 \mathrm{mM} \mathrm{KPO} 4(\mathrm{pH} 6.8), 1 \mathrm{mM}$ DTT, $1 \mathrm{mM}$ EDTA and $100 \mathrm{mM} \mathrm{KCl]}$. The protein was applied to a $1 \mathrm{ml}$ MonoS column and eluted using a linear $\mathrm{KCl}$ gradient (100-700 mM) with RecG eluting at $350 \mathrm{mM} \mathrm{KCl}$. The fractions containing RecG were pooled and dialyzed overnight against storage buffer [20 $\mathrm{mM}$ Tris-HCl (pH 7.5), $1 \mathrm{mM}$ EDTA, $1 \mathrm{mM}$ DTT, $100 \mathrm{mM} \mathrm{NaCl}$ and 50\%(v/v) glycerol]. The protein concentration was spectrophotometrically determined using an extinction coefficient of $49,500 \mathrm{M}^{-\mathrm{s}} \mathrm{cm}^{-\mathrm{c}(26)}$.

Single-strand DNA-binding protein was purified from strain $\mathrm{K} 12 \Delta \mathrm{H} 1 \Delta \operatorname{trp}$ as previously 
described (27). The concentration of purified SSB protein was determined at $280 \mathrm{~nm}$ using $\varepsilon=$ $30,000 \mathrm{M}^{-1} \mathrm{~cm}^{-1}$. The site size of SSB protein was determined to be 10 nucleotides per monomer by monitoring the quenching of the intrinsic fluorescence of SSB that occurs on binding to ssDNA, as described previously $(15,28)$.

\section{Preparation of fork DNA substrates.}

The fork DNA substrates were assembled from two duplexes and the core fork segment, similar to our previous methodology(16). Briefly, the core fork was made by annealing for short oligoes. Then the cork fork was ligated with two long duplexes on both sides. The core fork segment varied between the substrates to include one of the two the mismatches. The core segment

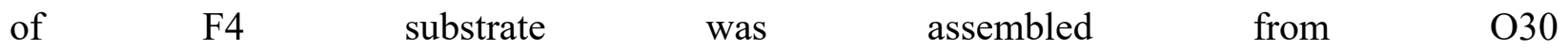

(TCATCTGCGTATTGGGCGCTCTTCCGCTTCCTATCT), $\quad 031$

(TCGTTCGGCTGCGGCGAGCGGTATCAGCTCACTCATA), $\quad 032$

(GCTTATGAGTGAGCTGATA

CCGCTCGCCGCAGCCGAACGACCTTGCGCAGCGAGTCAGTGAGATAGGAAGCGGAA

$\begin{array}{lll}\text { GAGCGCCCAATACGCAGA), } & \text { Ond }\end{array}$

(CACTGACTCGCTGCGCAAGGTCGTTCGGCTGCGGCGAGCGGCTA

ACATCTGGGTTTTCATTCTTTGGGTTTCACTTTCTCCAC). To assemble the core segment of

F6, O33 was replaced by O35 (CACTGACTCCCTGCGCAAGGCTAACAGCATCACAC ACATTAACAATTCTAACATCTGGGTTTTCATTCTTTGGGTTTCACTTTCTCCAC). To assemble the core segment of F7, O30 was replaced by O30-bulge (TCATCTGCGTATTGGGCGCTCTTCGCGCTTCCTATCT). For F8, O30 was replaced by O30mismatch (TCATCTGCGTATTGGGCGCTCTTCCCCTTCCTATCT). All other segments for F6, F7 and F8 are the same as for F4 substrate. All oligonucleotides were obtained from IDT 
(Integrated DNA Technologies, Inc. Coralville, Iowa, USA).

\section{Preparation of DNA-protein complexes.}

SSB-RecG-DNA complexes. DNA was mixed with the SSB tetramer in a molar ratio of 1:2 (DNA:SSB) and incubated in binding buffer [10mM Tris- $\mathrm{HCl}(\mathrm{pH} 7.5), 50 \mathrm{mM} \mathrm{NaCl}, 5 \mathrm{mM}$ $\mathrm{MgCl}_{2}, 1 \mathrm{mM}$ DTT] for $10 \mathrm{~min}$ at room temperature. RecG (4:1 molar ratio to DNA) was added into the mixture and incubated for additional $30 \mathrm{~min}$. The final molar ratio of DNA:SSB:RecG was $1: 2: 4$, and the final DNA concentration was $2 \mathrm{nM}$.

\section{The sample preparation and AFM imaging.}

APS functionalized mica was used as the AFM substrate for all experiments. Briefly, freshly cleaved mica was incubated in a $167 \mu \mathrm{M}$ aqueous solution of 1-(3-aminopropyl)silatrane (APS) for $30 \mathrm{~min}$ and rinsed thoroughly with deionized water as described in(16). Five microliters of the sample were deposited onto the APS mica for $2 \mathrm{~min}$, rinsed with deionized water, and dried with a gentle argon gas flow. Images were acquired using tapping mode in air on a MultiMode 8, Nanoscope V system (Bruker, Santa Barbara, CA) using TESPA probes (320 $\mathrm{kHz}$ nominal frequency and a $42 \mathrm{~N} / \mathrm{m}$ spring constant) from the same vendor.

\section{Data analysis.}

The AFM images were analyzed using the FemtoScan Online software package (Advanced Technologies Center, Moscow, Russia), which enables precise tracing of the DNA molecules. The position of each protein relative to the end of the short arm on the DNA substrate was measured. The total DNA length was then measured continuously to the other end of the DNA substrate. The yield of complexes was calculated from the ratio of protein-DNA complexes to the total number of DNA molecules. 


\section{Funding}

The work was supported by the National Institutes of Health (R01 GM100156 to YLL and PRB, R01 GM096039, R01GM118006 to YLL).

\section{Author contributions}

YLL, ZS, YW and MH conceived, designed the experiments. ZS purified the DNA constructs and collected AFM images, PRB provided all proteins, MH performed computational modeling. All authors wrote the manuscript.

\section{Acknowledgement}

Thank Thomas Stormberg for the discussion and writing of the manuscript.

\section{Completing financial interests}

The authors declare no competing financial interests.

\section{Supporting Information:}

Figures S1-S4. 


\section{Reference}

1. Kogoma, T. (1997) Stable DNA replication: interplay between DNA replication, homologous recombination, and transcription. Microbiology and molecular biology reviews : MMBR 61, 212-238

2. Kuzminov, A. (1999) Recombinational repair of DNA damage in Escherichia coli and bacteriophage lambda. Microbiology and molecular biology reviews : MMBR 63, 751-813, table of contents

3. Kowalczykowski, S. C. (2000) Initiation of genetic recombination and recombination-dependent replication. Trends in biochemical sciences 25, 156-165

4. Bhattacharyya, B., George, N. P., Thurmes, T. M., Zhou, R., Jani, N., Wessel, S. R., Sandler, S. J., Ha, T., and Keck, J. L. (2014) Structural mechanisms of PriA-mediated DNA replication restart. Proc Natl Acad Sci U S A 111, 1373-1378

5. Cox, M. M., Goodman, M. F., Kreuzer, K. N., Sherratt, D. J., Sandler, S. J., and Marians, K. J. (2000) The importance of repairing stalled replication forks. Nature 404, 37-41

6. Cox, M. M. (2001) Recombinational DNA repair of damaged replication forks in Escherichia coli: questions. Annual review of genetics 35, 53-82

7. Ryter, A., and Landman, O. E. (1964) Electron Microscope Study of the Relationship between Mesosome Loss and the Stable L State (or Protoplast State) in Bacillus Subtilis. J Bacteriol 88, 457-467

8. Manosas, M., Perumal, S. K., Bianco, P. R., Ritort, F., Benkovic, S. J., and Croquette, V. (2013) RecG and UvsW catalyse robust DNA rewinding critical for stalled DNA replication fork rescue. Nature communications 4, 2368

9. Buss, J. A., Kimura, Y., and Bianco, P. R. (2008) RecG interacts directly with SSB: implications for stalled replication fork regression. Nucleic Acids Res 36, 7029-7042

10. Slocum, S. L., Buss, J. A., Kimura, Y., and Bianco, P. R. (2007) Characterization of the ATPase activity of the Escherichia coli RecG protein reveals that the preferred cofactor is negatively supercoiled DNA. Journal of molecular biology 367, 647-664

11. Yu, C., Tan, H. Y., Choi, M., Stanenas, A. J., Byrd, A. K., K, D. R., Cohan, C. S., and Bianco, P. R. (2016) SSB binds to the RecG and PriA helicases in vivo in the absence of DNA. Genes Cells 21, 163-184

12. McGlynn, P., Mahdi, A. A., and Lloyd, R. G. (2000) Characterisation of the catalytically active form of RecG helicase. Nucleic Acids Res 28, 2324-2332

13. Peter, M., and Lloyd, R. G. (1999) RecG helicase activity at three- and four-strand DNA structures. Nucleic Acids Research 27, 3049-3056

14. Bianco, P. R., Pottinger, S., Tan, H. Y., Nguyenduc, T., Rex, K., and Varshney, U. (2017) The IDL of E. coli SSB links ssDNA and protein binding by mediating protein-protein interactions. Protein science : a publication of the Protein Society 26, 227-241

15. Ding, W., Tan, H. Y., Zhang, J. X., Wilczek, L. A., Hsieh, K. R., Mulkin, J. A., and Bianco, P. R. (2020) The mechanism of Single strand binding protein-RecG binding: Implications for SSB interactome function. Protein science : a publication of the Protein Society 29, 1211-1227

16. Sun, Z., Tan, H. Y., Bianco, P. R., and Lyubchenko, Y. L. (2015) Remodeling of RecG Helicase at the DNA Replication Fork by SSB Protein. Sci. Rep. 5, 9625

17. Sun, Z., Hashemi, M., Warren, G., Bianco, P. R., and Lyubchenko, Y. L. (2018) Dynamics of the Interaction of RecG Protein with Stalled Replication Forks. Biochemistry 57, 1967-1976

18. Abd Wahab, S., Choi, M., and Bianco, P. R. (2013) Characterization of the ATPase activity of RecG and RuvAB proteins on model fork structures reveals insight into stalled DNA replication fork repair. The Journal of biological chemistry 288, 26397-26409

19. Singleton, M. R., Scaife, S., and Wigley, D. B. (2001) Structural analysis of DNA replication fork reversal by RecG. Cell 107, 79-89

20. Tikhomirova, A., Beletskaya, I. V., and Chalikian, T. V. (2006) Stability of DNA Duplexes Containing GG, CC, AA, and TT Mismatches. Biochemistry 45, 10563-10571

21. Rossetti, G., Dans, P. D., Gomez-Pinto, I., Ivani, I., Gonzalez, C., and Orozco, M. (2015) The structural impact of DNA mismatches. Nucleic acids research 43, 4309-4321

22. Rossetti, G., Dans, P. D., Gomez-Pinto, I., Ivani, I., Gonzalez, C., and Orozco, M. (2015) The structural impact of DNA mismatches. Nucleic Acids Res 43, 4309-4321 
23. Zhu, J., and Wartell, R. M. (1999) The Effect of Base Sequence on the Stability of RNA and DNA Single Base Bulges. Biochemistry 38, 15986-15993

24. Tanaka, T., and Masai, H. (2006) Stabilization of a stalled replication fork by concerted actions of two helicases. J Biol Chem 281, 3484-3493

25. Buss, J., Kimura, Y., and Bianco, P. (2008) RecG interacts directly with SSB: implications for stalled replication fork regression. Nucleic Acids Res 36, 7029-7042

26. Gill, S. C., and von Hippel, P. H. (1989) Calculation of protein extinction coefficients from amino acid sequence data. Analytical biochemistry 182, 319-326

27. Lohman, T. M., Green, J. M., and Beyer, R. S. (1986) Large-scale overproduction and rapid purification of the Escherichia coli ssb gene product. Expression of the ssb gene under lambda $\mathrm{P}_{\mathrm{L}}$ control. Biochemistry 25, 21-25

28. Liu, J., Choi, M., Stanenas, A. G., Byrd, A. K., Raney, K. D., Cohan, C., and Bianco, P. R. (2011) Novel, fluorescent, SSB protein chimeras with broad utility. Protein science : a publication of the Protein Society 20, 1005-1020

Figure 1. The scheme of fork substrates. (A) The F4 construct contains 69nt ssDNA between the two perfectly paired DNA duplexes (280bp and 396bp). (B, C, D) The F6, F7 and F8 constructs, respectively, containing mismatches or bulges at different positions of the parental strand. (B) F6 contains a C-C mismatch 10 bp away from the fork. (C ) F7 contains a single G bulge $30 \mathrm{bp}$ upstream of the fork. (D) F8 contains a C-C mismatch $30 \mathrm{bp}$ away from the fork.

Figure 2. AFM images of SSB and RecG bound to various fork substrates are shown in (A) for F4, (B) for F6, (C) for F7 and (D) for F8. Double-feature complexes are indicated by arrows. The scale bar is $200 \mathrm{~nm}$. The insets (200 nm x $200 \mathrm{~nm})$ are the zoomed images of typical double-feature complexes; the blue arrows point to SSB, and the red arrows point to RecG protein.

Figure 3. Effect of SSB on the binding of RecG to various forks. Yields of SSB-RecG complexes with replication fork substrates were calculated in the absence (orange bars) and the presence of SSB (blue bars). In the absence of SSB, the binding efficiency of RecG on F4, F6, F7 and F8 substrates are $10.6 \pm 1.9 \%, 5.4 \pm 1.2 \%, 7.4 \pm 1.5 \%$ and $7.3 \pm 1.5 \%$, respectively. SSB 
increases the RecG binding efficiency to the fork DNA substrates to $27.4 \pm 5.3 \%, 11.6 \pm 4.1 \%$, $24 \pm 3.6 \%$ and $21.3 \pm 3 \%$, respectively.

Figure 4. Mapping of RecG positions relative to the SSB binding site. The map is constructed relative to the position of SSB bound to ssDNA of the replication fork. On the maps of SSB is indicated with triangles and RecG with circles. Frames A, B, C and D show positions of RecG on the DNA substrates F4, F6, F7 and F8, respectively. In 75\% of cases, RecG binds to the shorter duplex segment (parental) of the F4 construct. While in F6, F7 and F8 construct RecG binds to the longer segment (parental) of the DNA duplex $60 \%, 75 \%$ and $74 \%$ of the time. Histograms (E-H) show distributions of distances between RecG (on parental arms) and SSB measured which correspond to respective maps. Histograms were approximated with Gaussians and the values corresponding to maxima on these distributions are inserted in the histograms.

Figure 5. Snapshot of the RecG interacting with a stalled replication fork substrate after a $150 \mathrm{~ns}$ MD simulation. RecG wedge domain is colored purple, and the helicase domain is colored gray. DNA is colored orange and the segment between the wedge domain and helicase domain is in green, and the DNA interacting with the helicase domain is in red. The size of the green DNA is $10 \mathrm{nt}$ while the red is $13 \mathrm{nt}$. 
Figure1

\section{A Fork 4}

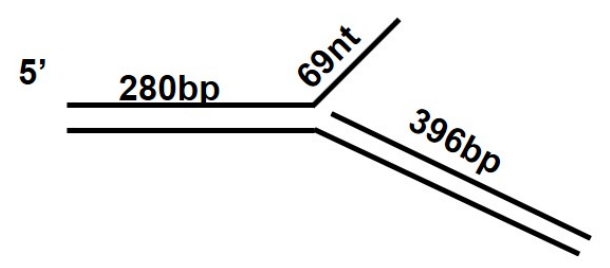

C Fork 7

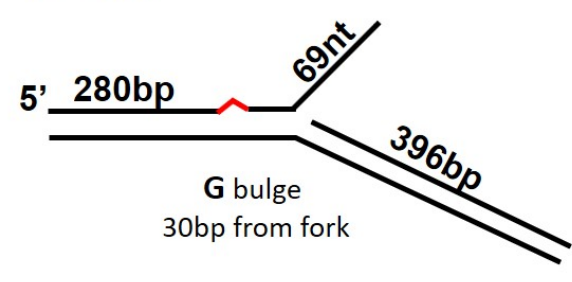

B Fork 6

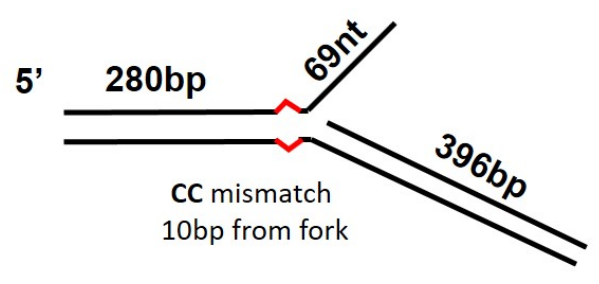

D Fork 8

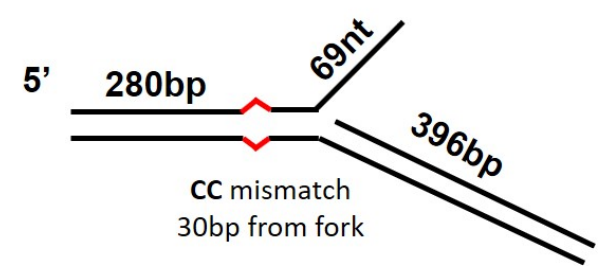


bioRxiv preprint doi: https://doi.org/10.1101/2021.03.31.437879; this version posted March 31, 2021. The copyright holder for this preprint (which was not certified by peer review) is the author/funder. All rights reserved. No reuse allowed without permission.

Figure 2
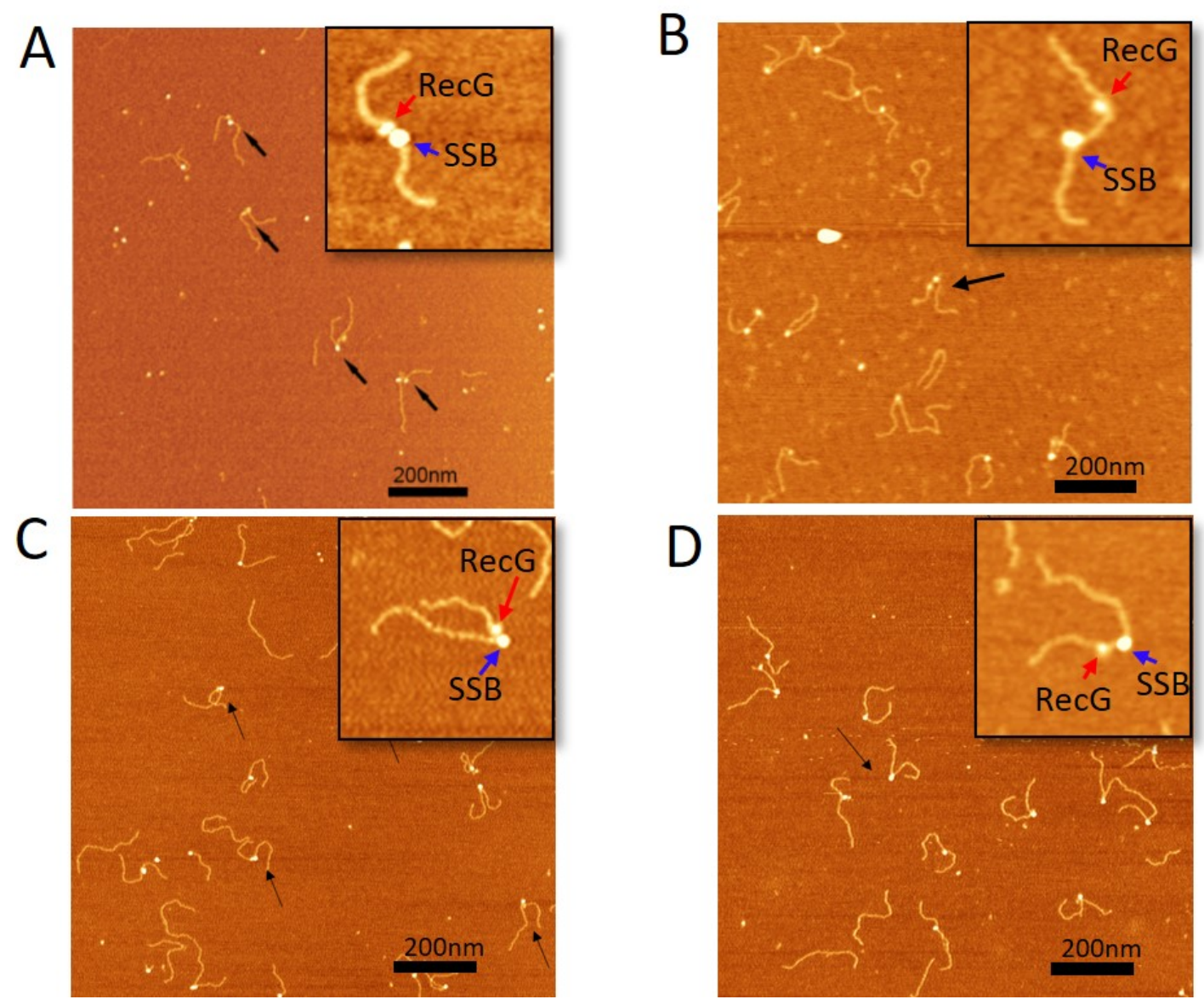
bioRxiv preprint doi: https://doi.org/10.1101/2021.03.31.437879; this version posted March 31, 2021. The copyright holder for this preprint (which was not certified by peer review) is the author/funder. All rights reserved. No reuse allowed without permission.

Figure 3

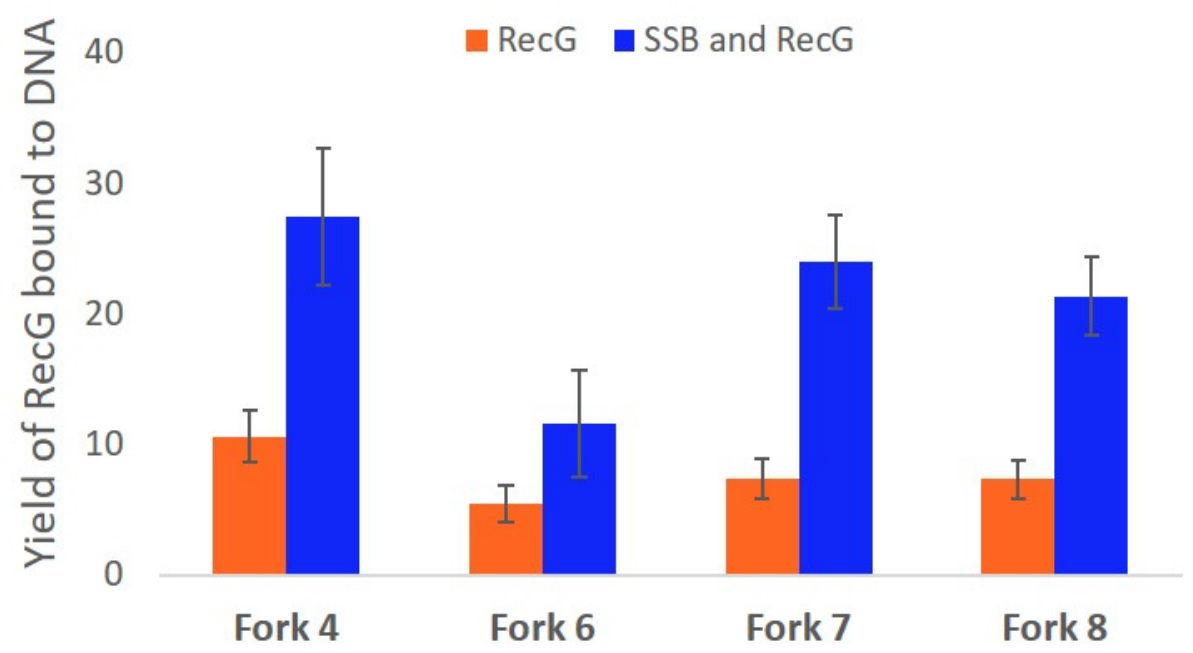


Figure 4
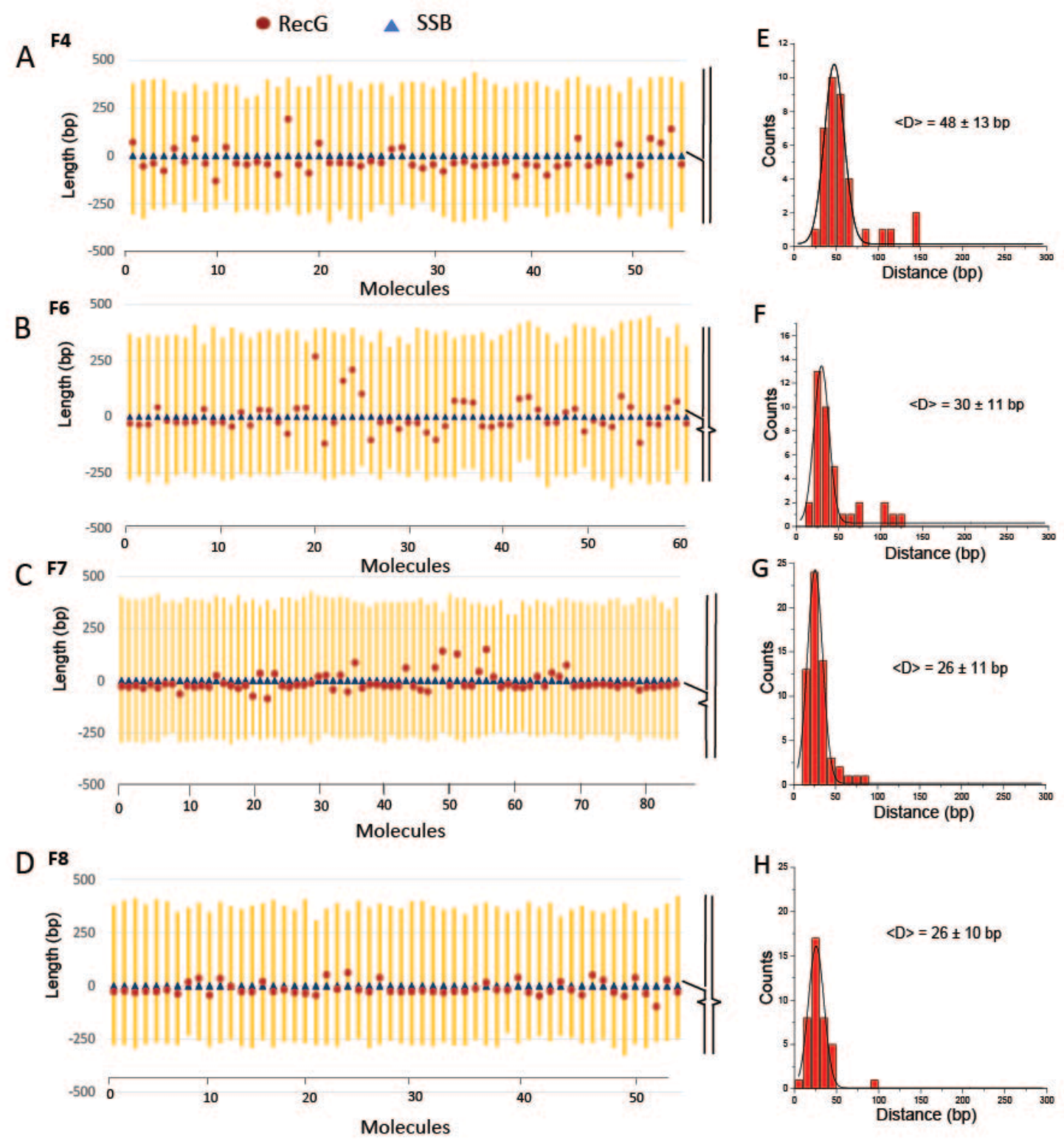
bioRxiv preprint doi: https://doi.org/10.1101/2021.03.31.437879; this version posted March 31, 2021. The copyright holder for this preprint (which was not certified by peer review) is the author/funder. All rights reserved. No reuse allowed without permission.

\section{Figure 5}

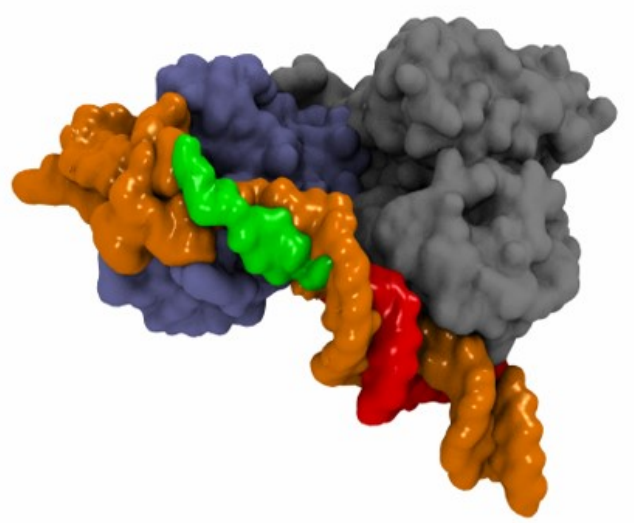

